\title{
Metastastic Gastric Adenocarcinoma: Diagnosis through Pericardioscopy
}

\section{Rodrigues GA*, Machado Lisboa JBR, Mondadori DC, De Freitas Filho 0 and Pêgo-Fernades PM}

Thoracic Surgery of Faculdade de Medicina da Universidade de São Paulo (FMUSP), Brazil

\section{Case Report \\ Volume 2 Issue 3}

Received Date: October 03, 2017

Published Date: October 12, 2017

*Corresponding author: Guilherme de Abreu Rodrigues, Thoracic Surgery of Faculdade de Medicina da Universidade de São Paulo (FMUSP), Av. Dr. Enéas de Carvalho Aguiar, 44, São Paulo, Brazil, Tel: 551126615000; E-mail: gui.armed@hotmail.com

\begin{abstract}
It is estimated that the pericardium is affected by 10 to $21 \%$ of patients with neoplasms. Malignant pericardial effusion is a complication that may be related to neoplastic disease in which, if not diagnosed and conducted rapidly, it may be life threatening requiring diagnosis. A 52-year-old female patient who, after having undergone pericardioscopy with pericardial biopsies to investigate pericardial effusion, obtained metastatic gastric adenocarcinoma, and gastric neoplasm with digestive endoscopy was confirmed.
\end{abstract}

Keywords: Gastric cancer; Pericarditis carcinomatosa; Cardiac tamponade; Pericardioscopy; Adenocarcinoma

\section{Introduction}

Pericardial effusion may result from conditions such as hypothyroidism, viral infections, and tuberculosis and heart post-procedure complications, cancers, among others. Often the pericardial effusion in patients diagnosed with cancer are identified as incidental findings on imaging studies, however it can cause symptoms to develop cardiac tamponade [1].

It is estimated that the pericardium is affected by 10 to $21 \%$ of patients with neoplasms [1]. Considering advanced gastric cancer, only $4.3 \%$ to $7.7 \%$ of cases have pericardial affection, lowing the chances of affection [2]. Only eight cases of cardiac tamponade related to gastric cancer metastatic were reported in PubMed between 1982 and 2010 [3].
The etiological diagnosis of lesions did through the pericardial cytology and microbiological studies have its limitations, being the biopsy the best investigative method [4]. A pericardioscopy watched video provides a better view of the biopsy site, increasing the diagnostic yield [4].

\section{Case Report}

MJP, female, 52 years old, sought medical attention with complaints of edema in the lower limbs for about 45 days followed by progressive dyspnea in the previous 10 days. On an initial evaluation, a chest tomography showed massive pleural effusion on the right and pericardial effusion. A transthoracic echocardiogram showed signs of restriction. The patient was submitted to pleural drainage with pig tail drainage having a removal of approximately $1300 \mathrm{ml}$ of citrus yellow secretion in a biochemical 


\section{Gastroenterology \& Hepatology International Journal}

analysis compatible with chylous effusion (Triglycerides $141 \mathrm{mg} / \mathrm{dl})$.

Subjected to pericardial drainage and biopsy in character of emergency, having drainage of $550 \mathrm{ml}$ of citrus yellow secretion. Anatomopathological analysis of the pericardium revealed mild fibrosis and mild perivascular lymphohistiocytic inflammatory infiltrated in cellular fluidity and could not exclude neoplastic affection.

She presented a good postoperative evolution, being discharged on the 33rd postoperative day with outpatient return for thoracic surgery. She underwent chest X-ray control, showing then a loculated effusion.

Since the patient still did not have a defined diagnosis, a pericardioscopy for biopsy and pulmonary decortication watched video (VATS) was indicated. A subxyphoid incision was made with dissection of the plans until the pericardium was thickened and thickened. After the pericardioscopy, a drainage of about $250 \mathrm{ml}$ of citrus yellow secretion and identified firm adhesions took place. Pericardial biopsies were performed guided by pericardioscopy followed by drainage. Following that, a decortication by VATS.

The patient progressed accordingly with anterior and posterior pleural drainage and mediastinal drainage with low flow. The anatomopathological result confirmed metastatic adenocarcinoma of probable primary site in gastrointestinal tract, with markers, infiltrating pericardium. The patient was referred to an oncology treatment institution, where gastric neoplasm was diagnosed as primary tumor through upper digestive endoscopy.

\section{Discussion}

In a review of 91 patients submitted to pericardioscopy in our institution along 9 years, our diagnosis was: nonspecific inflammation in $50(54.94 \%)$ cases, neoplastic diseases in $22(24.17 \%)$ cases, tuberculosis In 11 $(12.08 \%)$ cases, bacterial inflammatory process in 3 $(3,29 \%)$ cases, chylopericardium in $2(2,19 \%)$ cases, fungal infections in $2(2,19 \%)$ cases and viral infection in $1(1.09 \%)$ if [5].

Pour malignant pericardial is a complication that can be related to neoplastic disease on which, if not diagnosed and quickly conducted it can be potentially deadly [6]. The breast carcinoma, melanoma and lymphoma tumors are the most related to pericardial metastases. When affected with cardiac tamponade symptoms have major respiratory discomfort associated with chest pain, cough, among others [1].

The edema of the lower limbs and progressive dyspnea were the reasons for hospitalization of our patient. She presented changes in the gastrointestinal tract as initial symptoms.

In the diagnostic evaluation, malignant pericardial effusions had positive cytology in $50 \%$ to $80 \%$ of cases $[7,8]$. In order to identify the cause of the pericardial affection, a biopsy procedure was used.

In the cardiac tamponade approach, a subxyphoid pericardial drainage, a percutaneous drainage, a radio therapy, a systemic or local chemotherapy, and a pericardial window were used [3]. The use of intrapericardial sclerosing material is used in an attempt to prevent the recurrence of stroke, being effective when compared to isolated percutaneous drainage, except for the subxyphoid drainage, which verified that a surgery would be enough [3].

Due to the fast and safe subxyphoid drainage, a percutaneous drainage is reserved for patients at risk of life with hemodynamic instability [9].

In this specific case, the patient underwent a subxiphoid drainage, and no sclerosing material was used as a complement to prevent relapse. She presented satisfactory evolution without relapse of the effusion.

In this case, the use of pericardioscopy provided biopsies with satisfactory samples for diagnosis.

A study after considering 114 patients with cancer diagnosis and pericardial effusion cytological showed sensitivity on the studies of the pericardial fluid, the pericardial pathological exams and the pericardioscopy pericardial biopsy were $75 \%, 65 \%$ and $97 \%$ respectively [10].

In a series of 17 cases of cardiac tamponade related to gastric cancer, described by Kobayashi, it was found that patients who had developed cardiac tamponade before completing 2 years of the diagnosis of gastric neoplasia presented an average survival of 2.9 months and that the use of paclitaxel-based chemotherapy has been positive in the treatment of cardiac tamponade caused by 


\section{Gastroenterology \& Hepatology International Journal}

carcinomatous pericarditis related to gastric cancer $[11,12]$.

\section{Conclusion}

Pericardioscopy is an important option in the armamentarium for the diagnosis of pericardial effusion, allowing a better evaluation of the pericardium on direct vision and obtaining a sample for histopathological diagnosis, being able to elucidate rare cases such as metastatic gastric cancer.

\section{References}

1. Kunitoh $H$, Tamura $T$, Shibata T, Imai M, Nishiwaki $Y$, et al (2009) A randomized trial of intrapericardial bleomycin for malignant pericardial effusion with lung cancer (JCOG9811). Bri J Cancer 100(3): 464469.

2. Press OW, Livingston $\mathrm{R}$ (1987) Management of malignant pericardial effusion and tamponade. JAMA 257(8): 1088-1092.

3. Huang JY, Jiang HP, Chen D, Tang HL (2011). Primary gastric carcinoma presenting as cardiac tamponade. World J Gastrointest Oncol 3(4): 67-70.

4. Pêgo-Fernandes PM, Fernandes F, Ianni BM, Rohr SS, Bernardelli IM, et al. (2001) Video-Assisted Pericardioscopy. How to Improve Diagnostic Efficacy in Pericardial Effusions. Arq Bras Cardiol 77(5): 403406.

5. Pêgo-Fernandes PM, Mariani AW, Fernandes F, Ianni $\mathrm{BM}$, Stolf NG, et al. The role of video pericardioscopy in evaluating indeterminate pericardial effusions. Heart Surg Forum 11(1): E62-65.
6. Arısoy A, Memiç $\mathrm{K}$, Karavelioğlu $\mathrm{Y}$, Sen $\mathrm{F}$ (2014) Cardiac tamponade as the first clinical sign of gatric adenocarcinoma: a rare condition. Arch Turk Soc Cardiol 42(4): 377-379.

7. Gupta K, Mathur VS (2003) Diagnosis of Pericardial Disease Using Percutaneous Biopsy Case Report and Literature Review. Tex Heart Inst J 30(2): 130-133.

8. Fernandes F, Ianni BM, Arteaga E, Benvenutti L, Mady C ( 1998) Value of pericardial biopsy in the etiologic diagnosis of pericarditis. Arq Bras Cardiol 70(6): 393395.

9. Allen KB, Faber LP, Warren WH, Shaar CJ (1999) Pericardial Effusion: Subxiphoid Pericardiostomy Versus Percutaneous Catheter Drainage. Ann Thorac Surg 67(2): 437-440.

10. Abrão FC1, Bibas BJ, Pêgo-Fernandes PM, Jatene FB (2010) Usefulness of Pericardioscopy in the Diagnosis of Pericardial Effusion. Arq Bras Cardiol 94(5): e128-e130.

11. Porte HL, Janecki-Delebecq TJ, Finzi L, Methods DG, Millaire A, et al. (1999) Pericardoscopy for primary management of pericardial effusion in cancer patients. Eur J Cardiothorac Surg 16(3): 287-291.

12. Kobayashi M, Okabayashi T, Okamoto $\mathrm{K}$, Namikawa T, Araki K (2005) Clinicopathological study of cardiac tamponade due to pericardial metastasis originating gastric cancer. World J Gastroenterol 11(44): 68996904. 